\title{
Exchange-Rate Regimes and the Effectiveness of Fiscal Policy
}

\author{
Georgios Karras \\ University of Illinois
}

\begin{abstract}
How does the potency of fiscal policy depend on a country's exchange-rate regime? The Mundell-Fleming theoretical model predicts that fiscal policy can affect output under both fixed and flexible exchange rates, but that the effect is larger when the exchange rate is fixed. Using a panel data set of 61 countries for the 1951-2007 period, the paper shows that fiscal policy is indeed more potent under fixed exchange rates than under flexible, and that the difference is substantial: the estimated models imply that maintaining a fixed exchange rate raises the long-run fiscal multiplier by roughly a third.
\end{abstract}

- JEL Classification E62, F41

- Keywords: Fiscal Policy, Fixed or Flexible Exchange Rates.

\section{Introduction}

Because of the prominence of fiscal policy in recent stabilization efforts in countries of all shapes and sizes, the output effects of government spending have been the subject of numerous studies. ${ }^{1}$ However, very few of them, if any, have addressed the question of how the potency of fiscal policy may depend on a country's exchange-rate regime.

Theoretically, some guidance on this issue is offered by the Mundell-Fleming

*Corresponding address: Department of Economics, University of Illinois at Chicago, $601 \mathrm{~S}$. Morgan St., Chicago, IL 60607 7121; e-mail: gkarras@uic.edu.

@2011-Center for Economic Integration, Sejong Institution, Sejong University, All Rights Reserved.

'This literature is already very large, and it is also growing extremely rapidly, so only a partial list is possible. Theoretical contributions on the fiscal multiplier include Christiano, Eichenbaum, and Rebelo (2009), Eggertsson (2009), and Woodford (2010). For empirical contributions, see Barro and Redlick (2009), Cogan, Cwik, Taylor, and Wieland (2009), Hall (2009), and Mountford and Uhlig (2008). 
model which predicts that, though fiscal policy is effective under both fixed and flexible exchange rates (Prediction \#1), it should be more potent under fixed exchange rates than under flexible (Prediction \#2). The reason for the difference is simple. An increase in government spending will raise the interest rate, which, under a flexible exchange rate, will lead to an appreciation of the domestic currency, mitigating (though not eliminating) the fiscal expansion's initial effects on expenditure. On the contrary, under fixed exchange rates, and in order to prevent the domestic appreciation, monetary policy must also become expansionary, augmenting the fiscal expansion's initial effects on expenditure.

Despite its importance, however, empirical evidence on the influence of exchange-rate flexibility on the potency of fiscal policy has been virtually nonexistent. A recent exception is the influential study by Ilzetzki, Mendoza, and Vegh (2010), which finds that fiscal expansions are effective under fixed exchange rates, but completely ineffective under flexible. This, of course, is consistent with what was termed above as Mundell-Fleming's Prediction \#2, but it is inconsistent with Prediction \#1. Below, we will be referring to this as the Ilzetzki, Mendoza, and Vegh paradox.

The goal of the present paper is to contribute to the empirical side of this issue using a panel methodology that analyzes annual data from the 1951 to 2007 period for 61 developed and developing economies.

Our empirical findings show that fiscal expansions are indeed more effective under fixed exchange rates than under flexible, as predicted by the MundellFleming theoretical model. In fact the difference is quite sizable: the estimates suggest that adopting a fixed exchange rate increases the long-run fiscal multiplier by roughly a third. This appears to be primarily due to the response of private consumption which is found to be crowded out under flexible exchange rates, but crowded in under fixed. Moreover, our evidence clearly shows that fiscal expansions are effective under both fixed and flexible exchange rates, thereby resolving the Ilzetzki, Mendoza, and Vegh (2010) paradox in favor of the MundellFleming model's predictions.

Finally, the results imply that an increase in government spending crowds out private consumption under flexible exchange rates, but not under fixed rates, when consumption is actually increased. The effect of fiscal expansions on investment is also higher under fixed exchange rates, but the difference is less significant than for consumption.

The rest of the paper is organized as follows. Section II discusses the sources of 
the data and defines the variables to be used in the estimation. Section III outlines the estimation methodology, derives the main empirical results, and implements a number of robustness checks. Section IV discusses the findings and concludes.

\section{The Data}

The data set consists of a panel of 62 countries, for each of which annual data exist for all variables for each of the years 1950-2007.

All data on output, government purchases, and exchange rates are obtained from the Penn World Table (PWT, Mark 6.3), documented in Heston, Summers, and Aden (2009; see also Summers and Heston, 1991). Output $(y)$ is measured by real GDP, and government purchases $(g)$ are based on the constant-price government share of real GDP, both in PPP terms. ${ }^{2}$

We define a country's exchange rate in the current year as fixed if it is equal to both last year's and next year's exchange rate for the country. ${ }^{3}$ Otherwise, the exchange rate is defined as flexible. Note that this is a more precise definition than the one used by Ilzetzki, Mendoza and Vegh (2009), whose binary designation classifies a given country as having "fixed" or "flexible" exchange rates for the entire period. On the contrary, the present paper's definition allows countries to switch back and forth between exchange-rate regimes, a feature that we believe captures the properties of the data more realistically.

The Appendix provides a list of these 62 economies, together with country averages over the period 1951-2007 for the fixed and growth series. ${ }^{4}$ Note that by construction, each country's averaged fixed value, as reported in the Appendix, captures the fraction of the full (1951-2007) time period the country's exchange rate was fixed.

As the Appendix makes clear, our sample of countries is very diverse, including economies which are at various stages of development, and have experienced very different growth rates and degrees of exchange-rate flexibility. For example, the

${ }^{2}$ In terms of the PWT 6.3 terminology, $y=r g d p l^{*} p o p / 1000$ and $g=y^{*} k g / 100$, where $r g d p l$ denotes real GDP per capita (constant prices), $\mathrm{kg}$ is the government share of real GDP, and pop is population in thousands. As the data are all PPP-adjusted, the paper's findings should be interpreted as conditional on this measure of the series.

${ }^{3}$ Technically, using $E$ for the nominal exchange rate with respect to the U.S. dollar, we set fixed $_{i, t}=1$ when $E_{i, t-1}=E_{i, t}=E_{i, t+1}$; and fixed $_{i, t}=0$ otherwise. We experimented with alternative definitions, but our basic empirical results were robust (see section 3.4).

${ }^{4}$ Country selection has been dictated by data availability only. 
average annual growth rate of real GDP has ranged from $0.98 \%$ in the Democratic Republic of Congo to $7.98 \%$ in Taiwan. At the same time, the average value of fixed, i.e., the fraction of the 1951-2007 period that the exchange rate was fixed, has varied from zero (a fully flexible exchange rate) in Brazil or Canada, to one (a fully fixed exchange rate) in Ecuador or the dollarized Panama. ${ }^{5}$ It is apparent from the Appendix that the majority of the countries have average fixed values that are far from the two extremes of zero and one, suggesting that a binary classification of countries between fixed and flexible subsamples is neither as realistic nor as informative as the one used by the present paper.

\section{Empirical Evidence}

\section{A. A simple model}

We start with Hall's (2009) very simple empirical specification:

$$
\frac{y_{i, t}-y_{i, t-1}}{y_{i, t-1}}=w_{i}+v_{t}+m_{y} \frac{g_{i, t}-g_{i, t-1}}{y_{i, t-1}}+u_{i, t},
$$

where $y$ is real GDP, $g$ represents real government purchases, $i$ is indexing over countries and $t$ over time, $w$ and $v$ represent country- and time-specific effects, and $m_{y}$ is a parameters to be estimated. As noted by Hall (2009) and Barro and Redlick (2009), the form of equation (1) and the use of the same denominator on the leftand the right-hand sides, gives $m_{y}$ the normal interpretation of a "multiplier", capturing the output effects of an increase in government purchases by an additional unit.

The first three columns of Table 1 show that the estimated $m_{y}$ 's range from 0.89 to 0.98 , depending on how the $w_{i}$ 's are treated in the estimation. ${ }^{6}$ The estimated standard errors suggest that the multipliers are highly statistically significantly different from zero, but not statistically significantly different from one. ${ }^{7}$

To allow for the possibility that the multiplier differs under fixed and flexible rates, we rewrite equation (1) as:

\footnotetext{
${ }^{5}$ The sample mean of fixed is 0.249 , which means that one fourth of the sample's observations belong to years and countries that are classified as fixed.

${ }^{6}$ As in all following Tables, the first column (OLS) ignores the country and time effects, while the second and third columns model the w's and v's as fixed effects (FE), and random effects (RE), respectively. ${ }^{7}$ Numerically, therefore these estimates are closer to those of Barro and Redlick's (2009) than Hall's (2009).
} 


$$
\frac{y_{i, t}-y_{i, t-1}}{y_{i, t-1}}=w_{i}+v_{t}+m_{y} \frac{g_{i, t}-g_{i, t-1}}{y_{i, t-1}}+m_{f} \text { fixed }_{i, t} \frac{g_{i, t}-g_{i, t-1}}{y_{i, t-1}}+u_{i, t},
$$

where, as described in the previous section, fixed is the dummy variable that equals 1 when the exchange rate is fixed, and 0 when it is flexible. Therefore, (a positive) $m_{f}$ captures the degree to which the output multiplier is greater under fixed than under flexible exchange rates.

The last three columns of Table 1 report the estimated $m_{y}$ 's and $m_{f}$ 's, and unsurprisingly, the $m_{y}$ 's remain positive and statistically significant. In addition, the estimated $m_{f}$ 's are shown to be positive, sizable, and statistically significant. The estimated values imply that the fiscal multiplier under fixed exchange rates $\left(m_{y}+m_{f}\right)$ ranges from 1.11 to 1.27 , and is substantially and statistically significantly higher than the multiplier under flexible exchange rates $\left(m_{y}\right)$ which ranges from 0.82 to 0.90 . It appears that adopting a fixed exchange rate increases the multiplier roughly by a third. This is of course consistent with the prediction of the MundellFleming model.

Note, moreover, that the Ilzetzki, Mendoza and Vegh (2010) paradox is absent here because the multiplier under flexible exchange rates, though lower than it is under fixed rates, is clearly positive. ${ }^{8}$

\section{B. The benchmark dynamic model}

Models (1) and (2) may be a useful starting point, but a more realistic model

Table 1. Estimated $m_{y}$ and $m_{f}$

\begin{tabular}{|c|c|c|c|c|c|c|}
\hline & \multicolumn{3}{|c|}{ Model (1) } & \multicolumn{3}{|c|}{ Model (2) } \\
\hline & OLS & $\mathrm{FE}$ & RE & OLS & $\mathrm{FE}$ & $\mathrm{RE}$ \\
\hline$m_{y}$ & $\begin{array}{l}0.98^{* * *} \\
(0.05)\end{array}$ & $\begin{array}{l}0.89^{* *} \\
(0.05)\end{array}$ & $\begin{array}{l}0.91^{* *} \\
(0.05)\end{array}$ & $\begin{array}{l}0.90^{\text {** }} \\
(0.06)\end{array}$ & $\begin{array}{l}0.82^{\text {** }} \\
(0.06)\end{array}$ & $\begin{array}{l}0.85^{\text {** }} \\
(0.06)\end{array}$ \\
\hline$m_{f}$ & & & & $\begin{array}{l}0.37^{* *} \\
(0.12)\end{array}$ & $\begin{array}{c}0.29^{*} \\
(0.12)\end{array}$ & $\begin{array}{c}0.31^{*} \\
(0.12)\end{array}$ \\
\hline
\end{tabular}

Notes: "FE" denotes (country and time) Fixed effects and "RE" (country and time) Random Effects. Estimated standard errors in parentheses. $* *$ and $*$ denote statistical significance at the $1 \%$ and $5 \%$ significance levels.

${ }^{8}$ Put in terms of the present notation, Ilzetzki, Mendoza and Vegh (2010) find $m_{y}+m_{f}>m_{y}=0$, while the Mundell-Fleming model predicts $m_{y}+m_{f}>m_{y}>0$. Table 1 is consistent with both inequalilties of the Mundell-Fleming prediction. 
needs to include a richer dynamic structure. To that end, we start with the simplest dynamic specification:

$$
\frac{y_{i, t}-y_{i, t-1}}{y_{i, t-1}}=w_{i}+v_{t}+\sum_{j=0}^{J} m_{y, j} \frac{g_{i, t-j}-g_{i, t-j-1}}{y_{i, t-j-1}}+u_{i, t}
$$

where, in addition to the previously used notation, $J$ is the number of lags, and the $m_{y, j}$ 's are now the parameters to be estimated. Note that the long-run fiscal multiplier implied by this model is given simply by $\sum_{j=0}^{J} m_{y, j}$.

Table 2 reports the long-run multipliers estimated with model (3) for the full sample (ALL), and for the subsamples of Fixed- and Flexible-Exchange rates, for $J=4 .{ }^{9}$ All estimated multipliers are positive and statistically significant. In addition, it is clear that the multipliers under fixed exchange rates (ranging from 1.08 to 1.31 ) are found to be substantially higher than they are under flexible rates (0.82 to 1.23). Using the more reliable fixed- or random-effects estimates, it now appears that adopting a fixed exchange rate increases the multiplier by a substantial $30 \%$ to $45 \%$. This result is again consistent with the Mundell-Fleming prediction. Note, moreover, that the Ilzetzki, Mendoza and Vegh (2010) paradox is again resolved because the multiplier is significantly positive under flexible exchange rates, though clearly lower than it is under fixed rates.

Figure 1 reports the Impulse Response Functions implied by the fixed- and random-effects versions of model (3), together with one-standard deviation confidence intervals. These show the output effects to be higher under fixed exchange rates, but positive under both fixed and flexible rates.

The rest of this section investigates the robustness of these results. The most

Table 2. Long-Run Fiscal Multipliers, Model (3)

\begin{tabular}{llll}
\hline & OLS & FE & RE \\
\hline \multirow{2}{*}{ ALL } & $1.35^{* *}$ & $1.01^{* * *}$ & $1.12^{* *}$ \\
& $(0.11)$ & $(0.12)$ & $(0.11)$ \\
FIXED EXHANGE RATES & $1.31^{* *}$ & $1.08^{* *}$ & $1.22^{* *}$ \\
& $(0.25)$ & $(0.31)$ & $(0.26)$ \\
FLEXIBLE EXHANGE RATES & $1.27^{* *}$ & $0.83^{* *}$ & $0.83^{* *}$ \\
& $(0.12)$ & $(0.13)$ & $(0.06)$ \\
\hline
\end{tabular}

Notes: See Table 1.

${ }^{9}$ Different lag lengths were also tried, but results are very robust and are not reported to preserve space. 
Figure 1. Fiscal Multipliers under Fixed and Flexible Exchange Rates, Model (3)

\section{Fiscal Multipliers under Fixed and Flexible Exchange Rates}
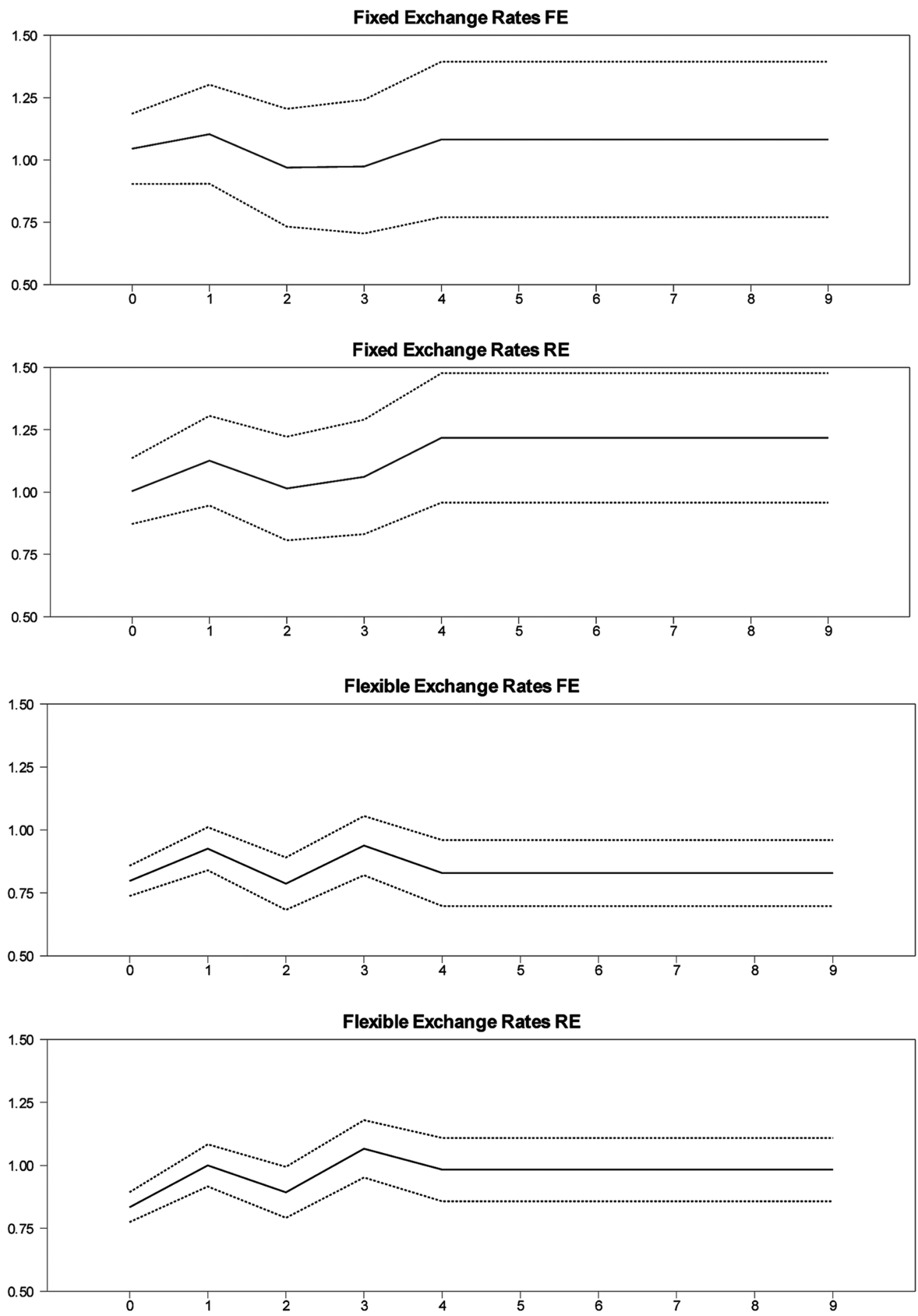

Notes: FE and RE denote Fixed and Random effects, respectively. Dotted lines are one-standard deviation significance bands. 
obvious correction has to do with the presence of serial correlation. ${ }^{10}$ To allow for this, we modify model (1) to:

$$
\frac{y_{i, t}-y_{i, t-1}}{y_{i, t-1}}=w_{i}+v_{t}+\sum_{j=1}^{J} \alpha_{j} \frac{y_{i, t-j}-y_{i, t-j-1}}{y_{i, t-j-1}}+\sum_{j=0}^{J} m_{y, j} \frac{g_{i, t-j}-g_{i, t-j-1}}{y_{i, t-j-1}}+u_{i, t}
$$

where the $\alpha$ 's are the autoregressive parameters to be estimated. Note that the long-run fiscal multiplier is now given by $\frac{\sum_{j=0}^{J} m_{y, j}}{1-\sum_{j=1}^{J} \alpha_{j}}$.

Table 3 estimates the long-run multipliers obtained from model (4). Once again, while all estimated multipliers are positive and statistically significant (so there is no Ilzetzki, Mendoza and Vegh (2010) paradox), the multipliers are substantially higher under fixed exchange rates (ranging from 1.07 to 1.30) than they are under flexible rates ( 0.80 to 1.13$)$. Once again, fixing the exchange rate raises the multiplier by about $30 \%$.

Figure 2 plots the Impulse Response Functions implied by the fixed- and random-effects versions of model (4), showing how the output response accumulates over time to a larger effect under fixed than under flexible exchange rates, regardless of whether the model is estimated with fixed or random effects.

\section{Additional Robustness Extensions}

Our measure of government purchases, like that of most of the related empirical

Table 3. Long-Run Fiscal Multipliers, Model (4)

\begin{tabular}{llll}
\hline & OLS & FE & RE \\
\hline \multirow{2}{*}{ ALL } & $1.23^{* * *}$ & $0.99^{* *}$ & $1.08^{* *}$ \\
& $(0.15)$ & $(0.13)$ & $(0.13)$ \\
FIXED EXHANGE RATES & $1.30^{* * *}$ & $1.07^{* *}$ & $1.19^{* *}$ \\
\multirow{2}{*}{ FLEXIBLE EXHANGE RATES } & $(0.27)$ & $(0.25)$ & $(0.25)$ \\
& $1.13^{* *}$ & $0.80^{* *}$ & $0.93^{* *}$ \\
& $(0.17)$ & $(0.15)$ & $(0.15)$ \\
\hline
\end{tabular}

Notes: See Table 1. Standard errors are estimated using the Delta Method.

\footnotetext{
${ }^{10}$ When we used $\rho$, the estimated $\operatorname{AR}(1)$ parameter for the residuals, as proposed by Wooldridge (2002), serial correlation was detected in both the FE and RE specifications. Instead of imposing a first-order structure, however, we prefer to allow for the more general form of model (2).
} 
Figure 2. Response of GDP to an increase in Government Spending, Model (4)

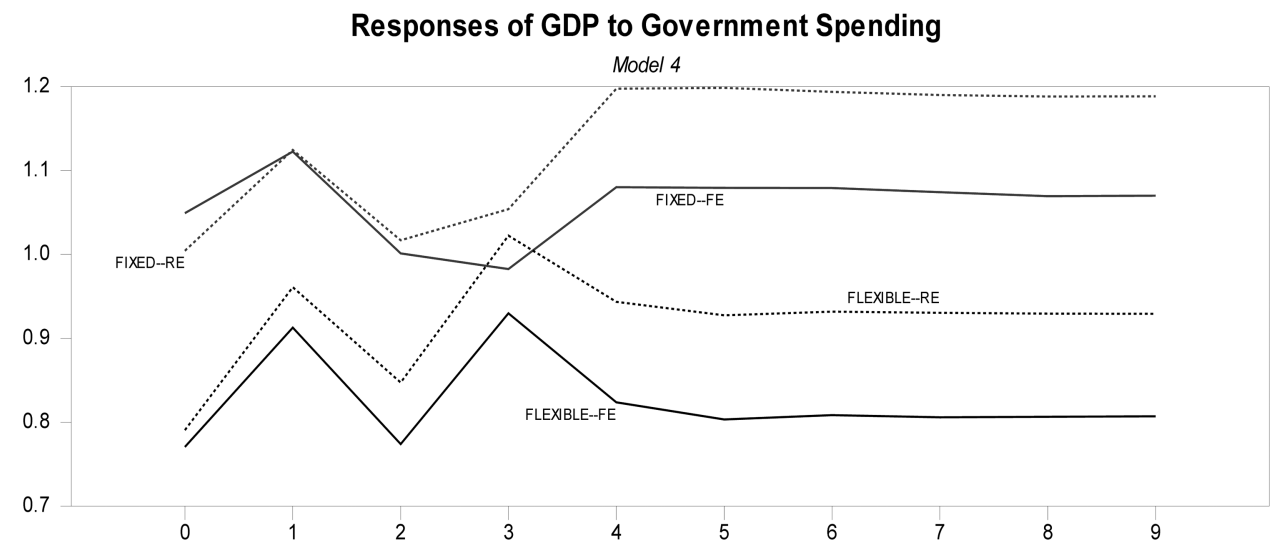

literature, is less likely to be exogenous than Hall's (2009) or Barro and Redlick's (2009) variable which relies on military expenditure. Our estimated $m_{y}$ 's in models (1) - (4), therefore, could be biased. One way to address this is to correct for the effects of economic activity on government purchases, estimating the VAR-type system of equations:

$$
\frac{g_{i, t}-g_{i, t-1}}{y_{i, t-1}}=s_{i}+z_{t}+\sum_{j=1}^{J} \beta_{j} \frac{y_{i, t-j}-y_{i, t-j-1}}{y_{i, t-j-1}}+\sum_{j=1}^{J} \delta_{j} \frac{g_{i, t-j}-g_{i, t-j-1}}{y_{i, t-j-1}}+u_{i, t}^{g}
$$

and

$$
\frac{y_{i, t}-y_{i, t-1}}{y_{i, t-1}}=w_{i}+v_{t}+\sum_{j=1}^{J} \alpha_{j} \frac{y_{i, t-j}-y_{i, t-j-1}}{y_{i, t-j-1}}+\sum_{j=0}^{J} m_{y, j} \hat{u}_{i, t-j}^{g}+u_{i, t}
$$

where $s$ and $z$ (like $w$ and $v$ ) represent country- and time-specific effects, and the

Table 4. Long-Run Responses to Exogenous Fiscal Shocks, Model (5)

\begin{tabular}{llll}
\hline & OLS & FE & RE \\
\hline \multirow{2}{*}{ ALL } & $1.53^{* *}$ & $1.21^{* *}$ & $1.27^{* *}$ \\
& $(0.21)$ & $(0.13)$ & $(0.17)$ \\
FIXED EXHANGE RATES & $2.43^{* *}$ & $1.44^{* *}$ & $2.34^{* *}$ \\
\multirow{2}{*}{ FLEXIBLE EXHANGE RATES } & $(0.54)$ & $(0.37)$ & $(0.48)$ \\
& $1.39^{* *}$ & $0.98^{* *}$ & $1.12^{* *}$ \\
& $(0.24)$ & $(0.19)$ & $(0.21)$ \\
\hline
\end{tabular}

Notes: See Table 1. Standard errors are estimated using the Delta Method. 
$\beta$ s and $\delta$ 's (like the $\alpha$ 's and $m_{y}$ 's) are parameters to be estimated. Equation (5b) is a special case of (4). Equation (5a) allows government spending to respond to economic growth, recognizing the fact that economic activity plays a role in the determination of government purchases. We interpret $\hat{u}_{i, t}^{g}$, estimated as the residual from regression (5a), as an "exogenous" fiscal shock.

We estimate the system of equations (5) and report in Table 4 the long-run multipliers. Somewhat surprisingly, these values are generally higher than the ones obtained when the raw variable was used in models (1) - (4). Nevertheless, the pattern is entirely unaffected: the long-run multipliers are higher under fixed exchange rates (ranging from 1.44 to 2.43 ) than under flexible rates (0.98 to 1.39), but they are statistically significantly positive under either regime. Figure 3 makes the same point looking at the impulse response functions.

Finally, we investigate the effects of government spending on the two main private expenditure components of GDP: private consumption (denoted here by $c$, typically the largest component) and investment (denoted by $i$, usually the most volatile component). We start with a simple specification along the lines of model (1):

$$
\frac{x_{i, t}-x_{i, t-1}}{y_{i, t-1}}=w_{i}^{x}+v_{t}^{x}+m_{x} \frac{g_{i, t}-g_{i, t-1}}{y_{i, t-1}}+u_{i, t}^{x},
$$

where $x=c$ or $i$, and the $m$ 's are the "multipliers" to be estimated. Next, to allow again for the possibility that the multipliers differ under fixed and flexible rates, we rewrite equation (6a) as:

Figure 3. Response of GDP to an exogenous change in Government Spending, Model (5)

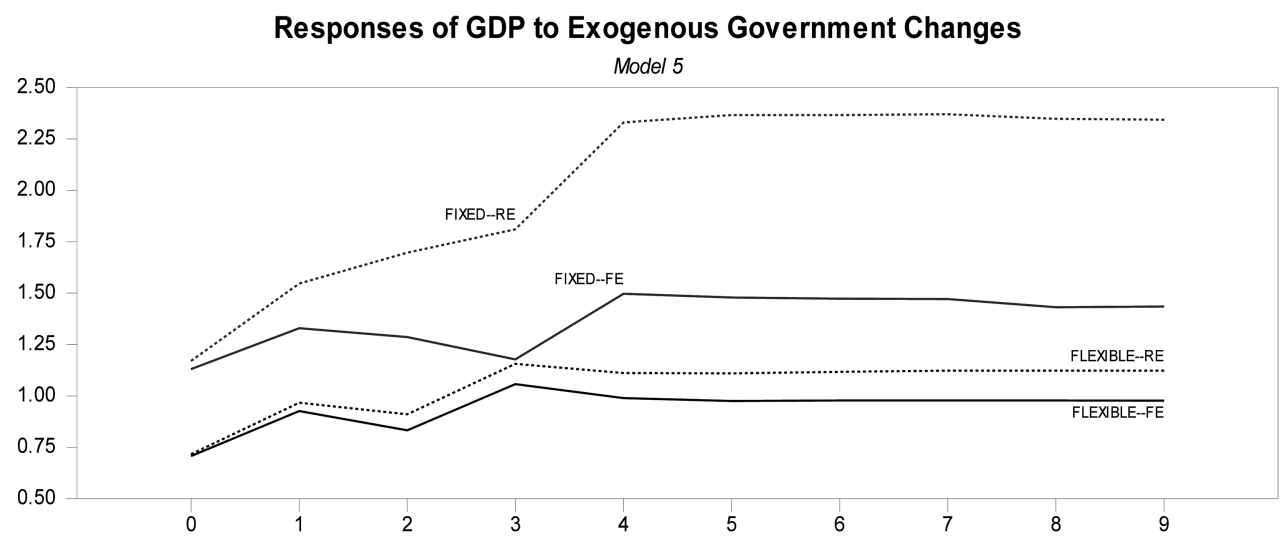


Table 5. Estimated "multipliers" for Consumption and Investment

\begin{tabular}{|c|c|c|c|c|c|c|}
\hline & \multicolumn{3}{|c|}{ Model (6a) - Consumption } & \multicolumn{3}{|c|}{ Model (6b) - Consumption } \\
\hline & OLS & FE & $\mathrm{RE}$ & OLS & FE & $\mathrm{RE}$ \\
\hline \multirow[t]{4}{*}{$m_{c}$} & $\begin{array}{c}-0.02 \\
(0.04)\end{array}$ & $\begin{array}{l}-0.10^{*} \\
(0.04)\end{array}$ & $\begin{array}{l}-0.08^{*} \\
(0.04)\end{array}$ & $\begin{array}{l}-0.11^{*} \\
(0.05)\end{array}$ & $\begin{array}{c}-0.17^{* *} \\
(0.05)\end{array}$ & $\begin{array}{c}-0.15^{* *} \\
(0.05)\end{array}$ \\
\hline & & & & $\begin{array}{l}0.37^{* * *} \\
(0.10)\end{array}$ & $\begin{array}{l}0.30^{* *} \\
(0.10)\end{array}$ & $\begin{array}{l}0.34^{* * *} \\
(0.10)\end{array}$ \\
\hline & \multicolumn{3}{|c|}{ Model (6a) - Investment } & \multicolumn{3}{|c|}{ Model (6b) - Investment } \\
\hline & OLS & $\mathrm{FE}$ & $\mathrm{RE}$ & OLS & FE & $\mathrm{RE}$ \\
\hline$m_{i}$ & $\begin{array}{l}0.34^{* *} \\
(0.04)\end{array}$ & $\begin{array}{l}0.33^{* *} \\
(0.04)\end{array}$ & $\begin{array}{l}0.33^{* *} \\
(0.04)\end{array}$ & $\begin{array}{l}0.32^{* *} \\
(0.05)\end{array}$ & $\begin{array}{l}0.30^{* *} \\
(0.05)\end{array}$ & $\begin{array}{l}0.30^{* *} \\
(0.05)\end{array}$ \\
\hline$m_{i, f}$ & & & & $\begin{array}{c}0.12 \\
(0.10)\end{array}$ & $\begin{array}{c}0.13 \\
(0.10)\end{array}$ & $\begin{array}{c}0.13 \\
(0.10)\end{array}$ \\
\hline
\end{tabular}

Notes : See Table 1 .

$$
\frac{x_{i, t}-x_{i, t-1}}{y_{i, t-1}}=w_{i}^{x}+v_{t}^{x}+m_{x} \frac{g_{i, t}-g_{i, t-1}}{y_{i, t-1}}+m_{x, f} \text { fixed }_{i, t} \frac{g_{i, t}-g_{i, t-1}}{y_{i, t-1}}+u_{i, t}^{x},
$$

which corresponds to model (2).

The results are given in Table 5. The top panel of Table 5 focuses on private consumption $(x=c)$. It shows that, when fixed or random effects are included, the estimated $m_{c}$ 's range from -0.02 to -0.17 . These negative coefficients suggest that there is crowding out of private consumption: higher government spending reduces the amount consumers spend. The estimated standard errors imply that these crowding out effects are (almost always) statistically significant. However, the estimated $m_{c, f}$ 's are shown to be positive, sizable, and statistically significant. The estimated values imply that the fiscal "multiplier" under fixed exchange rates $\left(m_{y}+m_{f}\right)$ ranges from 0.13 to 0.26 . This doesn't just mean that the "multiplier" is higher under fixed exchange rates - it also means that the crowding out of private consumption disappears, and it is actually reversed, under fixed exchange rates. Thus, an increase in government spending is associated with lower private consumption under flexible exchange rates, but higher private consumption if the exchange rate is fixed.

The bottom panel of Table 5 repeats the exercise for investment $(x=i)$. Now both $m_{i}$ 's and $m_{i, f}$ 's are positive, but only the $m_{i}$ 's are statistically significant. This means the following: government expansions raise private investment (no evidence 
of crowding out); the investment "multiplier" is greater under fixed than under flexible exchange rates; but the difference between the two is not statistically significant. Together with the results on consumption, this suggests that the reason the overall multiplier is larger under fixed exchange rates has more to do with the response of private consumption than that of investment.

To examine this further, several of the other models were also estimated for consumption and investment. To preserve space, we only describe those based on the VAR-type model (5), which we rewrite as:

$$
\frac{g_{i, t}-g_{i, t-1}}{y_{i, t-1}}=s_{i}+z_{t}+\sum_{j=1}^{J} \beta_{j} \frac{y_{i, t-j}-y_{i, t-j-1}}{y_{i, t-j-1}}+\sum_{j=1}^{J} \delta_{j} \frac{g_{i, t-1}-g_{i, t-j-1}}{y_{i, t-j-1}}+u_{i, t}^{g}
$$

and

$$
\frac{x_{i, t}-x_{i, t-1}}{y_{i, t-1}}=w_{i}+v_{t}+\sum_{j=1}^{J} \alpha_{x, j} \frac{x_{i, t-j}-x_{i, t-j-1}}{y_{i, t-j-1}}+\sum_{j=0}^{J} m_{x, j} \hat{u}_{i, t-j}^{g}+u_{i, t}^{x}
$$

where again $x=c$ or $i$. Equation (7a) is identical with (5a) and allows again government spending to react to economic activity. Equation ( $7 \mathrm{~b})$ is the analogue of (5b) for consumption and investment.

Figures 4 and 5 plot the Impulse Response Functions implied by the fixed- and random-effects versions of model (7), for consumption and investment, respectively. The two Figures paint a picture similar to that of the simpler results of

Figure 4. Response of Consumption to an exogenous change in Government Spending, Model (7)

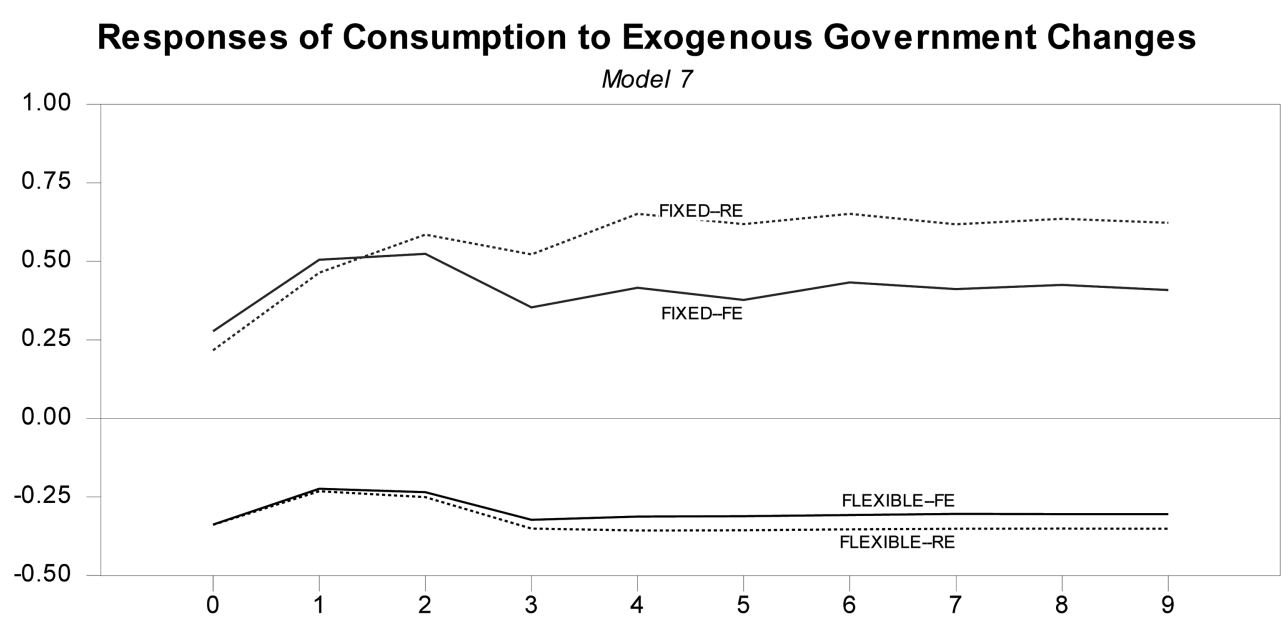


Figure 5. Response of Investment to an exogenous change in Government Spending, Model (7)

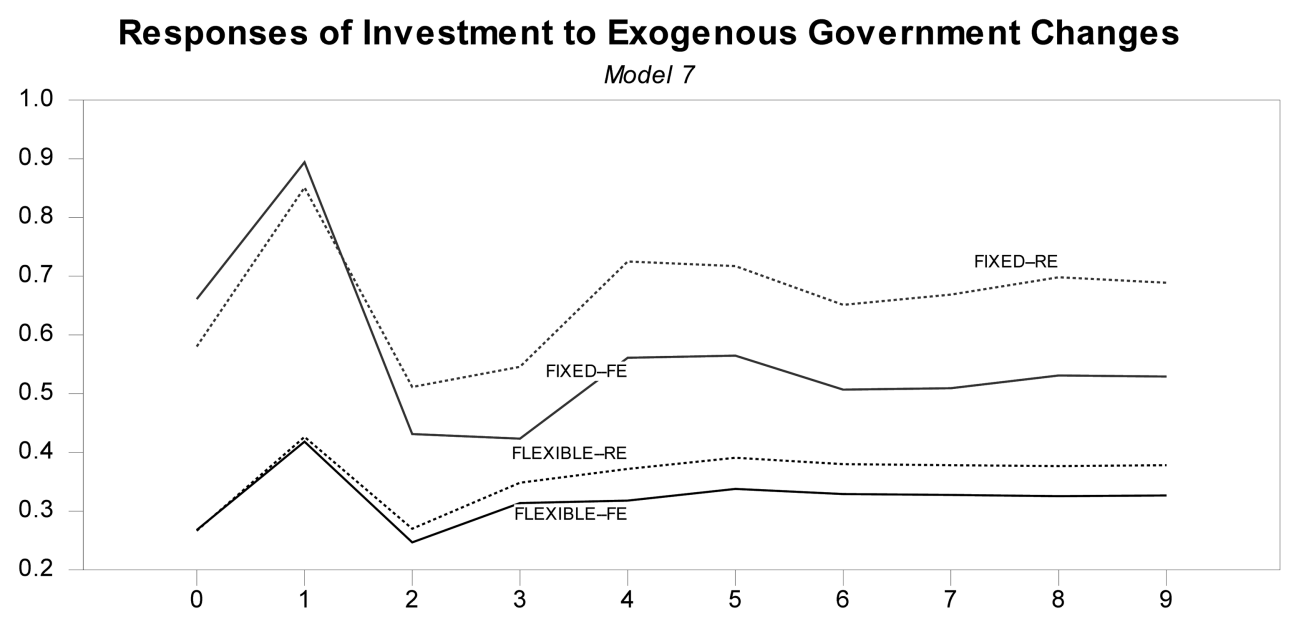

Table 5. In particular, Figure 4 shows that government expansions will crowd out private consumption under flexible exchange rates, but actually stimulate it under fixed. Figure 5 shows that private investment is not crowded out by higher government spending, but it responds more under fixed exchange rates than under flexible. These relationships are all robust to the inclusion of fixed or random effects.

In addition to the results described above, a number of other robustness checks have been implemented. In particular, we experimented with different lag lengths and different definitions of fixed, but the basic result has been robust.

\section{Discussion and Conclusions}

This paper asked whether the effectiveness of fiscal policy depends on a country's exchange-rate regime, as suggested by economic theory. Specifically, the Mundell-Fleming theoretical model predicts that a fiscal expansion will have a positive effect on output under both fixed and flexible exchange rates, but the effect should be larger under fixed exchange rates, because then the fiscal expansion has to be accompanied by expansionary monetary policy in order to prevent an appreciation of the domestic currency.

The paper used annual data from the 1951 to 2007 period, for 61 developed and developing economies, which exhibited varying degrees of exchange-rate 
flexibility. The empirical findings show that fiscal expansions are indeed more effective under fixed exchange rates than under flexible, as predicted by the Mundell-Fleming theoretical model. In addition, the difference is quantitatively substantial: the estimated models imply that maintaining a fixed exchange rate raises the long-run fiscal multiplier by roughly a third.

At the same time, however, the evidence also shows that fiscal expansions are effective under both fixed and flexible exchange rates, thereby resolving the Ilzetzki, Mendoza, and Vegh (2010) paradox in favor of the Mundell-Fleming model's predictions.

Finally, our findings suggest that government spending crowds out private consumption under flexible exchange rates, but not under fixed rates, when consumption is actually increased when government spending increases. The effect of fiscal expansions on investment is similarly higher under fixed exchange rates, but the difference is not as significant as it is for consumption. ${ }^{11}$ It appears, therefore, that the response of consumption holds the key to understanding the different effects of government spending under fixed and flexible exchange rates. This appears to be a promising avenue for future research.

Received 18 February 2010, Revised 27 January 2011, Accepted 31 January 2011

\section{References}

Barro, Robert J. and Charles J. Redlick (2009), Macroeconomic Effects from Government Purchases and Taxes, NBER Working Paper No. 15369, September.

Cogan, John F., Tobias Cwik, John B. Taylor, and Volker Wieland (2009), New Keynesian versus Old Keynesian Government Spending Multipliers, ECB Working Paper No. 1090, September.

Christiano, Lawrence, Martin Eichenbaum, and Sergio Rebelo (2009), When Is the Government Spending Multiplier Large?, NBER Working Paper No. 15394, October.

Hall, Robert E. (2009), By How Much Does GDP Rise if the Government Buys More Output?, NBER Working Paper No. 15496, November, forthcoming in the Brooking Papers on Economic Activity.

Heston, Alan, Robert Summers, and Bettina Aden (2009), Penn World Table, Version 6.3., Center for International Comparisons of Production, Income, and Prices at the University of Pennsylvania (CICUP), August.

Ilzetzki, Ethan, Enrique G. Mendoza, and Carlos A. Vegh (2010), How big (small?) are

\footnotetext{
${ }^{11}$ This test was partly motivated by the comments and suggestions of an anonymous referee.
} 
fiscal multipliers?, NBER Working Paper No. 16479, October.

Mountford, Andrew and Harald Uhlig (2008), What Are the Effects of Fiscal Policy Shocks?, NBER Working Paper No. 14551, December.

Summers, Robert and Alan Heston (1991), The Penn World Table (Mark 5): An expanded Set of International Comparisons, 1950-1988., Quarterly Journal of Economics, 106, 327-368.

Woodford, Michael (2010), Simple Analytics of the Government Expenditure Multiplier, NBER Working Paper No. 15714, January.

Wooldridge, J.M. (2002), Econometric Analysis of Cross-Section and Panel Data. MIT Press, Cambridge, Massachusetts.

\section{Appendix}

\section{List of Countries and Sample Means}

\begin{tabular}{|c|c|c|c|c|c|}
\hline & fixed & growth & & fixed & growth \\
\hline 1. Argentina & 0.07 & $2.73 \%$ & 32. Kenya & 0.23 & $3.63 \%$ \\
\hline 2. Australia & 0.14 & 3.92 & 33. Luxembourg & 0.21 & 3.84 \\
\hline 3. Austria & 0.25 & 3.63 & 34. Mauritius & 0.10 & 4.02 \\
\hline 4. Belgium & 0.19 & 3.04 & 35. Mexico & 0.26 & 4.74 \\
\hline 5. Bolivia & 0.30 & 2.42 & 36. Morocco & 0.14 & 4.67 \\
\hline 6. Brazil & 0.00 & 5.13 & 37. Netherlands & 0.16 & 3.32 \\
\hline 7. Canada & 0.00 & 3.79 & 38. New Zealand & 0.10 & 3.04 \\
\hline 8. Chile & 0.00 & 4.22 & 39. Nicaragua & 0.50 & 3.69 \\
\hline 9. China & 0.28 & 7.45 & 40. Nigeria & 0.23 & 4.23 \\
\hline 10. Colombia & 0.05 & 4.22 & 41. Norway & 0.17 & 3.62 \\
\hline 11. Congo, D. R. & 0.28 & 0.98 & 42. Pakistan & 0.25 & 5.01 \\
\hline 12. Costa Rica & 0.26 & 5.08 & 43. Panama & 1.00 & 5.30 \\
\hline 13. Cyprus & 0.12 & 5.28 & 44. Paraguay & 0.37 & 3.83 \\
\hline 14. Denmark & 0.08 & 2.96 & 45. Peru 1951 & 0.17 & 3.93 \\
\hline 15. Dominican Rep & 0.58 & 5.62 & 46. Philippines & 0.03 & 4.76 \\
\hline 16. Ecuador & 1.00 & 4.46 & 47. Portugal & 0.26 & 4.17 \\
\hline 17. Egypt & 0.30 & 5.17 & 48. Puerto Rico & 1.00 & 4.88 \\
\hline 18. El Salvador & 1.00 & 3.49 & 49. South Africa & 0.21 & 3.77 \\
\hline 19. Ethiopia & 0.41 & 3.52 & 50. Spain & 0.10 & 4.67 \\
\hline 20. Finland & 0.16 & 3.63 & 51. Sri Lanka & 0.10 & 4.66 \\
\hline 21. France & 0.21 & 3.47 & 52. Sweden & 0.17 & 2.72 \\
\hline 22. Greece & 0.28 & 4.17 & 53. Switzerland & 0.28 & 2.82 \\
\hline 23. Guatemala & 0.60 & 3.96 & 54. Taiwan & 0.25 & 7.98 \\
\hline 24. Guyana & 0.25 & 1.41 & 55. Thailand & 0.07 & 5.92 \\
\hline 25. Honduras & 0.57 & 3.77 & 56. Trinidad \&Tobago & 0.25 & 4.84 \\
\hline 26. Iceland & 0.17 & 4.52 & 57. Turkey & 0.26 & 5.18 \\
\hline
\end{tabular}




\begin{tabular}{lcclcc} 
& fixed & growth & fixed & growth \\
\hline 27. India & 0.14 & 4.81 & 58. Uganda & 0.32 & 3.69 \\
28. Ireland & 0.10 & 4.27 & 59. United Kingdom & 0.08 & 2.63 \\
29. Israel & 0.16 & 6.00 & 60. United States $\left(^{*}\right)$ & 1.00 & 3.43 \\
30. Italy & 0.21 & 3.64 & 61. Uruguay & 0.01 & 2.25 \\
31. Japan & 0.19 & 5.27 & 62. Venezuela & 0.12 & 4.08 \\
\hline
\end{tabular}

Notes: fixed is the fraction of the 1951-2007 time period the country has been under fixed exchange rates according to the definition in the text; growth is the average annual growth rate of real GDP. (*) The US is excluded from the estimation sample because the definition of fixed would classify it as having fixed exchange rates for the entire period. 